\title{
Do Labour Market Reforms Achieve a Double Dividend under EMU? Discretionary versus Rule-based Monetary Policy Revisited
}

\author{
Ansgar Belke \\ Ruhr-Universitaet B ochum \\ Martina Kamp \\ Ruhr-Universitaet B ochum
}

\begin{abstract}
High equilibrium unemployment and the inflation bias in some EU countries require fundamental reforms of labour-market institutions. Impacts of different monetary regimes insi de and outside EMU on the incentives for labour-market reforms are examined in a Barro-Gordon framework from the perspective of a single country. M onetary policy (discretionary versus rule-based) and the degree of labour-market reforms are determined simultaneously. It can be shown that discreti onary policy outsi de EMU leads to a higher degree of reforms than rulebased policy since in the former case reforms reduce both unemployment and the inflation bias. H owever, rulebased monetary policy inside EMU limits the bene fits of reforms to a positive impact on employment. Never theless, total economy

* Correspondence Address: Dr. Ansgar Belke, Ruhr-Universität Bochum, Theoretische Volkswirtschaftslehre I, GC 3/147, D-44780 Bochum, Germany; (E-mail) ansgar.belke@ruhr-uni-bochum.de. We are grateful to the anonymous referees. Earlier versions of this paper have been presented at the Annual M eeting of the European Public Choice Society (EPCS), 7th to 10th April 1999, Lisboa/ Portugal, and at the Annual Conference of the European Association of Labour E conomists (EALE), 23th to 26th September 1999, Regensburg/ Germany.
\end{abstract}

( 1999 - Institute for International Economics, Sejong Institution. All rights reserved. 
welfare under EMU is superi or to the one under discretionary policy. Insofar as a superior instrument is available for the parallel reduction of the equilibrium inflation rate, namely a strict monetary policy rule, the higher degree of labourmarket reforms under di scretionary monetary policy outside EMU only signals a kind of an overshooting. (JEL Classifications: E52, E61, J38) ४Key

Words: European M onetar y Union, inflation bias, labor market reform, monetary policy regime, political economy of structural unemployment>

\section{Introduction}

In the current academic and political discussion both the permanently high level of unemployment and the choice of an appropriate monetary policy strategy represent aspects of considerable interest. In the public debate both aspects are often causally connected. However, in economic model building it has been neglected up to now to provide rational arguments for this presumed relation. Up to now, the incentives and disincentives for reforms on the European labour markets and the utility and costs of monetary policy rules have been analyzed in most cases separately.

On the one hand, the pros and cons of different monetary policy strategies have usually been investigated in the framework of the models by Barro and Gordon [1983] and [1983a] as well as by Kydland and Prescott [1977]. These contributions mainly focus on the time inconsistency problem of discretionary monetary policy. Efficiency gains of different monetary policy rules and potential losses induced by the inflexibility of rules in the wake of exogenous shocks are compared. As possible solutions to the tradeoff between the necessity of a flexible monetary policy to absorb stochastic shocks and the necessity of a rule-based monetary policy to cure the timeinconsistency problem, different kind of flexible rules have been proposed (Walsh [1995], Persson and Tabellini [1993], Svensson [1997]). Feedbackrules in connection with distinct commitment technologies, as e.g. the independence of central banks or incentive schemes for central bankers, are all part of it. However, the first-best solution undoubtedly is to remove labour market rigidities, the main cause of high structural unemployment (Svensson [1997], p. 104 and 109). However, one drawback of this proposal lies in the fact that it can be regarded as rather naive from a public choice perspec- 
tive. Namely, it is often overlooked that the arrangement and the regulation of labour market institutions-as an outcome of rational political choice -have to be implemented in the loss function of politicians. In this contribution, it is argued that the present design of labour market institutions can best be interpreted as the result of decisions of utility maximizing politicians. Therefore, the framework of time-inconsistency models should be extended to consider explicitly the degree of labour market reforms.

On the other hand, the determinants of labour market institutions, as e.g. labour market rigidities, have most recently been discussed from a public choice perspective. Usually, real instead of monetary models have been used for this purpose. A direct relation between demand policies and labour market rigidities - as emphasized in this contribution - is disregarded, though. These real models serve as a basis for formally testing the hypothesis that labour market institutions are not only determined by efficiency considerations but also by the interests of political majorities (Saint-Paul [1993, 1996]). They examine why significant reforms are far from being implemented in European labour markets although it is widely recognized that unemployment in Western E urope is rather a structural than a cyclical phenomenon (Calmfors [1998], Nickell [1997] and that efficient reforms are regarded as the only solution to that problem.

It can be shown that this rather isolated examination of the two aspects labour market reforms and monetary policy strategies - incorporates severe theoretical weaknesses. Consequently, it is rather difficult to forecast the probability of success of a change in monetary policy regime in combination with a reduction of high structural unemployment in Western Europe (Belke [1997]).

Likewise, a cross-country study is not ver y helpful to accomplish this forecast. It cannot replace a coherent theoretical analysis as done in this contribution. On the one hand, the U.S. are one example for a monetary union with labour market institutions that encourage a low natural rate of unemployment. On the other hand, the strong commitment to the EMS has not been able to help B elgium and France - in contrast to the $\mathrm{N}$ etherlands and perhaps also Denmark - to implement and to adhere to an extensive reform program. Finally, the U.K. and New Zealand are both examples for countries in which extensive labour market reforms were implemented without being involved 
in international exchange rate arrangements. Nevertheless both countries have in the past been characterized by strictly anti-inflationary monetary regimes (Belke [1998a], Belke [1999], Calmfors [1998]).

However, several attempts to assess the choice of monetary policy strategies and their incentive effects on the labour market were undertaken only recently in the political debate to predict the effects of European M onetary Union (EMU). This variant of a rule-based monetary policy leads - according to the current debate - to disciplinary impacts on national labour markets. The usual justification for this runs as follows. EM $U$ extends the credibility of monetary policy. Thus, inflation expectations decrease. Negative employment impacts as a result of high wage claims can no longer be accommodated by discretionary monetary policy. The responsibility of wage negotiating parties for unemployment increases significantly because they no longer negotiate about nominal wage growth but real wage growth. The responsibility for existing unemployment is more transparently assigned to the parties which negotiate about the relative price of labour. Discretionary monetary policy, however, hinders the removal of labour market rigidities, because the possibility remains to solve or at least to shift the unemployment problem on third parties by expansive monetary policy. ${ }^{1}$ The incentives for extensive reforms dwindle (Alogoskoufis [1994], Calmfors et al. [1997], M elitz [1997], Sibert and Sutherland [1997]). "This kind of argumentation has almost obtained the character of a folk theorem in the EM U discussion. It can be seen as a version of M rs. Thatcher's There-Is-N o-Alternative (TINA) strategy: if demand policy is immobilized, the policy maker has little option to undertake reform" (Calmfors [1998], p. 28). The hypothesis of disciplinary wage effects of a monetary policy rule is, however, not only discussed with regard to EMU:" ... in Germany labour understands the limited inflation tolerance of the Buba and, as a result, practices wage restraints so as to avoid unemployment" (D ornbusch and Favero [1998], p. 38).

H owever, there seems to be at least some agreement concerning the fact

1. Beetsma and Bovenberg [1998] implicitly argue that fiscal policy is more probably involved in such a process outside than inside EM U since fiscal policy of each individual country exerts only a relatively small effect on union-wide monetary policy within EMU. 
that the result of a reform encouraging effect of monetary policy rules is by no means necessary. First, Calmfors [1997] and Sibert and Sutherland [1997] argue that one expects too much from monetary policy with its mainly short run real effects to diminish structural unemployment significantly. In the same vein, empirical analysis give reason to believe that the capability and the necessity of intra-E uropean exchange rates to absorb asymmetric shocks on EU labour markets is rather low (Belke [1998], p. 259 ff., Belke and Goecke [1999], and Belke and Gros [1997, 1998]). Second, some papers which will be introduced below support the view that rule-based monetary policy has no disciplinary effects on the wage setting process, but strengthens the incentives to claim high wages on the part of the unions.

In a game theoretic setting, Cukierman and Lippi [1998] assess the interaction between central bank independence and the degree of centralization of wage negotiations and the effects on inflation and employment. In contrast to the traditional time-inconsistency literature it is assumed that unions, dependent on the degree of centralization, tend to internalize the effects of their decisions on the decision process of central bankers respectively on inflation. A diminishing degree of centralization reduces the extent to which unions take the strategic effects of their actions into consideration. That's why highly centralized wage setting parties produce relatively low real wages and low natural unemployment if the central bank pursues a discretionary regime. The reason is that unions do not have to fear that high wage claims are compensated by high inflation rates.

In this contribution, it is emphasized that the implementation of specific monetary policy rules significantly changes the framework necessary for the possibility and for the efficiency of structural reforms (Calmfors [1997, 1998], Gruner and Hefeker [1996], Belke [1997b, 1998a, 1999]). The assessment of different monetary policy rules from the employment perspective is dependent on their specific role in the implementation of labour market reforms: do they release or hinder labour market reforms? M oreover, it is decisive whether discretionary policy is able to settle the dispute between interest groups and to influence the efficiency of structural reforms positively. In the section II, a simple monetary model of employment in the tradition of B arro and Gordon [1983] and Kydland and Prescott [1977] is presented. However, it is augmented by one parameter representing the degree of 
labour market reforms. In the section III the analytical results are derived in this framework and are then summarized. In the section IV, the welfare of different monetary regimes is simulated and a welfare comparison is added. The section $V$ summarizes the results in view of several model extensions. The last section ends up with a conclusion.

\section{The Model}

In the following, we critically assess the often maintained view that the impacts of a change in the character of monetar $y$ regimes on the probability of labour market reforms are not predictable and speculative in the light of the Lucas critique (Belke [1998b]). In the framework of the Barro and Gordonmodel, labour market reforms are edosenized. ${ }^{2}$ Apart from the inflation rate and the unemployment rate, labour market reforms (and implicitly also the reforms in other areas relevant to the labour market, e.g. the goods markets and the social security system) are introduced as a bad in the loss function.

Politicians suffer from welfare losses by implementing labour market reforms. First, reforms at least in the short run reduce the wages of employed insiders, a group, which is frequently organized in powerful syndicates (trade unions) and which is relevant political majority for re-election. Rigid respectively non reformed labour markets induce welfare gains for insiders at the outsiders' expense. Outsiders are, as experience shows, compensated by active labour market policies and high public transfers (Belke [1997]). The inclusion of labour market reforms in the loss function can also be interpreted as the explicit consideration of the tax load which is necessary to finance such programs. ${ }^{3}$ Second, an own value is attached to existing labour market regulation, since they diminish the susceptibility of the

2. This specification is legitimized through the assumption of rational expectations. The analytical framework is given by Barro and Gordon [1983], Barro and Gordon [1983a], Kydland and Prescott [1977], Sibert and Sutherland [1997] and Svensson [1997]. The following model has its roots in Belke [1997b, 1998a], Belke and Kamp [1999] and Calmfors [1997].

3. This consideration is consistent with current observations for continental Europe. No political party reveals an ideological commitment for the imposition of reforms. See Belke [1997, 1998b], Berthold and Fehn [1996]. 
employed to shocks (protection against unlawful dismissal) or since they inherently bear an insurance character (as in case of unemployment benefits) (Belke [1997], Berthold and Fehn [1996], Calmfors [1998], Saint-Paul [1993, 1996]).

Formally, an additional secondary condition, apart from the usual Lucas type unemployment equation and the hypothesis of rational expectations, is introduced into the model (and is considered in the Lagrange-procedure). According to this new condition, the natural unemployment is linearly dependent on the chosen degree of labour market reforms. The following considerations distinguish between two scenarios for a representative economy: the case of discretionary monetary policy and the case of rule-based monetary policy.

In order to formally interpret the degree of labour market reforms as a rational political choice of politicians, the loss function used in the Barro and Gordon-model is augmented as follows:

$$
L=1 /\left[(\alpha u-\hat{u})^{2}+\left(-{ }^{\wedge}\right)^{2}+r^{2}\right]
$$

$u$ is the actual unemployment, $u$ is the unemployment target, $\pi$ is the actual inflation rate, $\hat{\pi}$ is the inflation target and $r$ corresponds to the actual degree of labour market reforms ( $r \geq 0)$. F or the reason of simplification, the separability of the loss function is assumed although there are also cases where the marginal utility of a reform is dependent of the level of unemployment (see e.g. Saint-Paul [1996]).

As unemployment equation an expectation augmented Phillips-curve is used:

$$
\begin{aligned}
u & =u^{*}-\left(-{ }^{e}\right)+\text { with } \\
& =E(\quad) .
\end{aligned}
$$

$\mathrm{u}^{*}$ is the natural rate of unemployment, $\pi^{\mathrm{e}}$ is the rationally expected inflation rate and $\varepsilon$ is an stochastic i.i.d. shock. The parameter $\beta$ characterizes the extent of nominal wage rigidities, i.e. the intensity with which real wages react to non-anticipated changes in the price level. If the government intends to reduce the inflation rate by one percentage point per year it has to accept $\beta$ additional percentage points of unemployment. Therefore, $\beta$ can also be described as the sacrifice ratio (Layard, J ackman and Nickell [1994], 
pp. 84 f.).

An additional significant deviation from the standard Bar ro-Gordon-model results from the quite realistic assumption that the level of the natural rate of unemployment depends on the chosen degree of labour market reform $r$ in a linear fashion:

$$
u^{*}=\tilde{u}-r
$$

$\tilde{u}$ is the level of natural unemployment in the absence labour market reforms $(r=0)$ and $\delta$ represents the marginal effectiveness of structural reforms with respect to the reduction of structural unemployment. ${ }^{4}$

In the following, a one-period game will be analyzed where politicians determine labour market institutions and monetary policy. Decisions about the arrangement of labour market institutions must be made before stochastic exogenous shocks are realized. They have to be met under consideration of the inflation-reaction function. Once the decision on the labour market arrangement is made it is irreversible. ${ }^{5}$ However, higher degrees of freedom are - as usual in this kind of models - ascribed to monetary policy. The latter is assumed to be able to react to a stochastic shock within a period and can stabilize such a shock.

4. Alternatively (or additionally), labour market reforms could have effects on the measure of nominal wage rigidities $\beta$ (parameter in the Phillips-curve). A reduction of $\beta$ in the wake of labour market reforms would be plausible since labour market reforms tend to reduce the reaction of unemployment to inflation surprises. One should pay attention to the fact that the flexibility of nominal wages is connected to the cyclical sensitivity of unemployment. However, nominal wage flexibility is of less importance for the level of structural unemployment.

5. Nevertheless, no 'option value of waiting' is considered referring to the level and the timing of the reforms, although a 'wait and see'-strategy might be advantageous when uncertainty about the consequences of reforms according to investment theory (real options) prevails. See Belke and Goecke [1999].

6. M cCallum [1995] and Jensen [1997] both refer to the problem that the combination of "delegation and proper incentive schemes" is not able to eliminate the inflation bias completely as long as discretionary national stabilization policy is maintained (cf. chapter III.B). 


\section{Results}

\section{A. Credible Commitment to a Strict Monetary Policy Rule}

In order to develop a reference scenario, it is assumed that national politicians can be obliged to a credible and optimal monetary policy rule. This could be attained by the membership in EMU, assuming that the European central bank is less willing to accept inflation than other countries do (Calmfors [1998], p. 29). ${ }^{6}$ The optimization problem consists of identifying a monetary policy rule (i.e. of selecting a reaction function for the inflation rate) and of simultaneously identifying the degree of labour market reforms in a way that the loss function in equation ( 1 ) is minimized. ${ }^{7}$ The values of $\pi, \pi^{\mathrm{e}}$ and $r$ which minimize equation (1) with respect to equation (2) and (4) under the assumption of rational expectations $\left(\pi^{\mathrm{e}}=\mathrm{E}(\pi)\right)$ must be computed.

In the case of equality of the natural and the targeted level of unemployment $\left(u^{*}=\hat{u}\right)$ the politicians choose the same inflation rate as an optimal monetary policy rule would achieve (Barro and Gordon [1983a], p. 597, Svensson [1997], pp. 101 ff.). The optimization must, therefore, be carried out with respect to the restriction $u^{*}=\hat{u}$. Considering rational expectations and substituting $\pi^{\mathrm{e}}$ the optimal monetary policy rule yields:

$$
=\hat{}+\left(/\left(+{ }^{2}\right)\right) \text {. }
$$

In the optimum, a constant inflation target is pursued. Exogenous shocks are, however, stabilized by deviations from the inflation target. On average, neglecting the i.i.d. shocks ${ }^{8}$, the degree of labour market reform amounts to:

$$
-\left(u^{*}-\hat{u}\right)+r=0
$$

or equivalently to:

$$
r^{*}=(\tilde{u}-\hat{u}) /\left(+{ }^{2}\right) .
$$

7. Concerning the structure of the game, the expected loss function should be minimized. But for the reason of clearity the expectations operator is left out.

8. Strictly speaking, the monetary rule can in this case simply be expressed as a k-percent rule without feedback component. 
Equations (6) and (6a) have interesting implications. The degree of labour market reforms $r$ is chosen such that the marginal utility of a lower equilibrium unemployment (in the form of the deviation of targeted unemployment weighed with the marginal efficiency of structural reforms $\left(-\delta\left(u^{*}-\hat{u}\right)\right)$ is equal to the marginal costs of reforms $(\gamma r)$. A sensitivity analysis reveals that these results make sense also from an economic point of view. The degree of structural reforms is positively related to the level of structural unemployment respectively the deviation of structural from the politically targeted unemployment $\left(\delta r^{*} / \delta \tilde{u}>0\right)$. The degree of structural reforms is never theless negatively related to the marginal costs of reforms $\left(\delta r^{*} / \delta \gamma<0\right)$. Simultaneously, the degree of structural reforms is independent of the nominal level of rigidities ( $\left.\delta r^{*} / \delta \beta=0\right)$.

\section{B. Discretionary Monetary Policy: Time Inconsistency of Optimal Monetary Policy}

From the empirical literature on the time inconsistency problem of optimal monetary policy it is well-known that it is realistic to model the economic decision process of discretionary monetary policy as a two-stage game. In the first stage, wage contracts are fixed on the basis of expected inflation. M oreover, the degree of labour market reforms is determined and exogenous stochastic shocks are realized. In the second stage, monetary policy sets course in a discretionary way. One reason to suppose a discretionary character of the game is given by the low possibility of successfully implementing credible commitments to an ex ante optimal monetar y policy.

The optimization approach to our model essentially remains the same as in the commitment case. The equation to determine $\pi^{\text {opt }}$ is unchanged. However, the solution is more complicated because in the discretionary case it is not presupposed that $u^{*}=\hat{u}$. Considering rational expectations and substituting $\pi^{\mathrm{e}}$ the following monetar $y$ reaction function comes out:

$$
{ }^{\wedge}+(/)\left(u^{*}-\hat{u}^{\prime \prime}\right)+\left(/\left(+{ }^{2}\right)\right) \text {. }
$$

In comparison to the commitment case, the additional term $(\beta / \lambda)\left(u^{*}-\hat{u}\right)$ stands for the time inconsistency problem. Some more aspects of this result shed some light on the relation between different monetary regimes and 
labour market reforms. It is significant that the degree of inflation bias is not only dependent on $\lambda$ but also on parameters which - directly or indirectly are related to labour market reforms. First, there is the dependence on natural unemployment $u^{*}$ which is according to equation (4) directly and negatively influenced by labour market reforms. Second, the sacrifice ratio $\beta$ considerably affects the level of inflation bias. However, also this determinant can be influenced by labour market reforms and by the resulting higher wage flexibility.

In the first stage of the game, politicians decide on the degree of reforms, taken the inflation reaction function as given. They select $r$ in such a way that the expected loss function (1) is minimized under the conditions of equations (2), (4) and (7). In contrast to section II, the reaction function for the inflation rate is directly implemented in the loss function and not added as an additional condition. The politicians have to consider the dependence of equilibrium inflation rate on the level of natural unemployment when fixing the degree of structural reforms $r$. However, the realization of the stochastic shock is recognized not until the ex ante optimal degree of reforms are fixed. Therefore, not only the stochastic part of equation $(7)-\left(\hat{\pi}+(\beta / \lambda)\left(u^{*}=\hat{u}\right)\right)$ is used. After optimization, the degree of reform is:

$$
r-\left(u^{*}-\hat{u}\right)-\frac{2}{2}\left(u^{*}-\hat{u}\right)=0
$$

respectively:

$$
*=\frac{\left({ }^{2}+\right)}{{ }^{2}\left({ }^{2}+\right)+}(\tilde{u}-\hat{u}) .
$$

In equation (6b), the marginal utility of lower equilibrium unemployment equals the marginal cost of reform. In comparison to the commitment case, an additional marginal utility component, $-\beta^{2} \delta\left(u^{*}-\hat{u}\right) / \lambda$, is contained. It can be directly put down to the utility increase of the reduction of the inflation bias $(\beta / \lambda)\left(u^{*}-\hat{u}\right)$ which is induced by the implementation of reforms. M ost important, it can be shown that the degree of structural reforms is less in the commitment case than in the case of discretionary monetary policy. For that purpose, the right-hand-side of equation ( $6 c$ ) - the degree of reforms under discretionary policy - and the right-hand-side of equation (6a) - the degree of reforms under commitment - are compared. 


$$
\begin{aligned}
& \frac{\left({ }^{2}+\right)}{{ }^{2}\left({ }^{2}+\right)+}(\tilde{u}-\hat{u})-\frac{}{\left(+^{2}\right)}(\tilde{u}-\hat{u})= \\
& {\left[\frac{\left({ }^{2}+\right)}{{ }^{2}\left({ }^{2}+\right)+}-\frac{\left({ }^{2}+\right)}{{ }^{2}\left({ }^{2}+\right)+\left({ }^{2}+\right)}\right](\tilde{u}-\hat{u})>0 ?}
\end{aligned}
$$

Obviously, this inequality is fulfilled because $\gamma\left(\beta^{2}+\lambda\right)$ in the denominator of the second fraction is larger than $\gamma \lambda$ in the denominator of the first fraction. B oth fractions only differ by these two parts. The degree of reforms is therefore higher in the case of discretion and lower in the case of commitment.

W ith discretionary monetary policy, labour market reforms seem to achieve a double 'dividend'. On the one hand, they reduce - as rule-based monetary policy - the costs of structural unemployment. On the other hand, they lessen equilibrium inflation since they diminish the credibility problem of discretionary monetary policy. The second effect does not exist in the case of rule-based monetary policy. Rule-based monetary policy does ex definitione not suffer from a credibility problem. However the question remains how relevant the case of discretionary monetary policy and therefore the second part of the 'dividend' in Western is in European reality? Otherwise, nothing could be inferred fro $m$ the results on the welfare effects of $E M U$.

Can it be supposed that national monetary policy outside EMU (the latter as a region of a uniform monetary policy rule) tends to be discretionary and thus suffers from an inflation bias although monetary policy is carried out by, at least in some cases, independent central banks (B ean [1998])? The fact that the cur rent convergence of inflation rates on a low level applies to the whole EU-region might be used as an argument against this interpretation. M oreover, some theoretical proposals which suggest methods to eliminate the inflation bias have been mentioned already in the introduction to this contribution. Incentive schemes are propagated which do not hinder optimal stabilization efforts of monetary policy.

Some arguments by M cCallum [1995] and Jensen [1997], however, support the hypothesis of a monetary policy which is more discretionary outside EMU. According to our model, this hypothesis is equivalent to the conclusion that reforms are lower in EMU-member countries than outside EMU. 
The above mentioned authors refer to the problem that the combination of delegation and proper incentive schemes is not able to eliminate the inflation bias of monetary policy completely, as long as a discretionary national stabilization policy is maintained. The assumption that a government which has already delegated monetary policy because of incentive problems accomplishes a contract with a central bank, achieving an optimal monetary policy which the government cannot provide, leads to an internal contradiction.

M oreover, it can be explained theoretically that the observed reduction of inflation rates and perhaps also the increasing independence of national central banks can be interpreted as mere temporary phenomena. They are possibly only introduced with the intention to qualify for EMU or at least to leave this opportunity open (Ozkan, Sibert and Sutherland [1997]). From this perspective, the second part of the maintained 'dividend' of discretionary monetary policy - additional labour market reforms to reduce the inflation bias - is also relevant in Western European reality prior to EM U respectively is still relevant in EMU-out-countries after the start of EMU. However, nothing is said yet on whether discretionary monetary policy, though, leads to a higher total welfare than a monetary policy rule, e.g. in the form of EMU. An additional assessment of total welfare effects follows in chapter IV. First of all, some formal results concerning the 'dividends' of labour market reforms under different monetary policy regimes are graphically presented to provide a better intuition with regard to the formal results gained so far.

\section{Graphical Exposition of the Results}

The relation between labour market reforms and the credibility problem of discretionary monetary policy can be clarified by figure 1. It is mainly based on the now generally accepted methodology by Layard, Jackman and Nickell [1994] and Lindbeck [1992]. ${ }^{9}$

9. A first application in the context of labour market reforms and monetary policy regimes is supplied by Calmfors [1988], p. 31. "N owadays, this general type of organisational framework for macroeconomic analysis of the labour market is shared by adherents of different theories of wage setting behavior ..." (Lindbeck [1992], p. 216). For a related figure see Berthold and Fehn [1998], p. 9, as well. 
Figure 1

\section{Labour Market Reforms and Equilibrium Inflation}

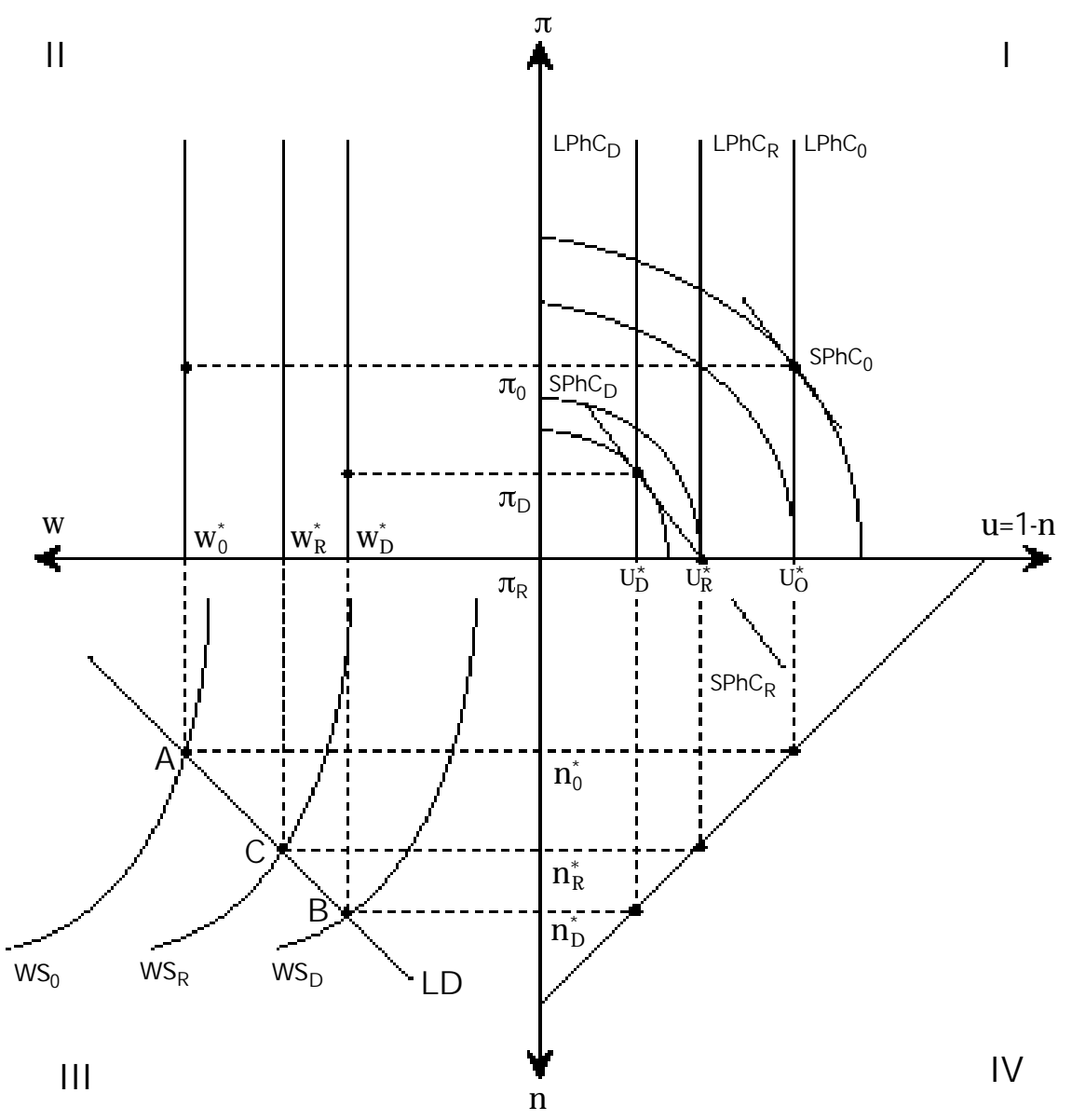

Figure 1 consists of four quadrants. The structural or equilibrium rate of unemployment is determined in the labour market ( $Q$ uadrant III). Labour demand is negatively dependent on the level of real wages $w$. The wage setting curve is, however, positively sloped. This can be easily justified by insider-outsider considerations or efficiency wage theories (Layard, Jackmann and Nickell [1994], p. 34 ff.).

In the case of insider-outsider theories for example, real wages are the higher the more favorable the respective 'outside opportunity' appears to wage-negotiating parties. On the one hand, unions have to consider a high- 
er risk of dismissal with higher real wages. On the other hand, favorable outside opportunities for the unemployed limit the competition between insiders and the unemployed. The contracting effect of union employment targets on wage-push factors corresponds to rational behavior since the shocks in the model cannot be anticipated by definition. Therefore, real wage demands are negatively correlated with the level of unemployment and positively correlated with the level and the length of the granting of unemployment benefits. It follows directly that a higher employment level $n$ expands the bargaining power of insiders so that they can push through higher real wages. M oreover, real wages cannot be set below the reservation wage $\mathbf{w}_{0}^{r}$. The reservation wage is determined above all by the length of public unemployment benefits. For the reason of clarity in exposition, the real reservation wages $w_{0}^{r}, w_{D}^{r}$ and $w_{R}^{r}$ are not explicitly mentioned in figure 1. But they can be thought of as points of intersection between the extension of the wage setting curves $W S_{0}, W S_{D}$ and $W S_{R}$ with the real wage axis $w$.

Point $A$, the intersection between the labour demand and the wage-setting curve, simultaneously determines the equilibrium rate of employment $\mathrm{n}_{0}^{*}$ (under the assumption of a constant employment potential), the equilibrium rate of unemployment $u_{0}^{*}=1-n_{0}^{*}$, and the equilibrium real wage $w_{0}^{*}$. According to the loss-function (1), politicians are inflation and unemployment averse. Their preferences can be described by a bundle of negatively sloped, concave indifference curves. The nearer the curve is located to the origin, the lower is the corresponding level of losses.

Nominal rigidities $\beta$ allow the government to achieve temporary employment gains in an environment of a negatively sloped short-run Phillipscurve by producing unexpected inflation. However, if wage-setters know the preferences of the government they set nominal wages in a way that there is no incentive any more for the government to induce unexpected inflation. Point A, the tangential of short-term and long-term Phillips-curve with the indifference lines of the government determines the equilibrium rate of inflation in the case of discretionary monetary policy without the possibility of structural reforms $\left(\pi_{0}\right)$. In this equilibrium with rational expectations, real wages are exclusively determined in the labour market. The respective functional relationship is described by a vertical line in quadrant I.

Labour market reforms can be best outlined by a shift of the wage setting 
curve in the direction of the employment axis. The shift can be explained by those factors emphasized by insider-outsider theories as arguments for the specific slope of the wage setting curve. A reform could e.g. reduce the period in which the unemployed receive unemployment benefits, a highly significant determinant of diverging unemployment rates in OECD countries (Belke and Koesters [1999], Calmfors [1998], Koesters and Belke [1996], Nickell [1997]). The real reservation wage of the unemployed would drop proportionally to the degree of reforms to $\mathrm{w}_{\mathrm{R}}^{*}$ respectively $\mathrm{w}_{\mathrm{D}}^{*} \cdot{ }^{10}$ The variable $\mathrm{w}_{\mathrm{D}}^{*}$ corresponds to the equilibrium real wage in the case of discretionary monetary policy.

The shift of the wage setting curve induced by labour market reforms is, in accordance with the computations in chapter III, lower in the case of a rule-based monetary policy than in the case of discretionary monetary policy. The negotiation power of insiders is reduced for every given employment rate. The labour market equilibrium in point $C$ determines the level of equilibrium employment $n_{R}^{*}$, the equilibrium real wage $w_{R}^{*}$ and the equilibrium rate of unemployment $u_{r}^{*}$. The long-term Phillips-curve moves to the left to $\mathrm{LPhC}_{\mathrm{R}}$.

Similar arguments are valid in the case of discretionary monetary policy. The shift of the wage setting curve, which comes out to be larger under a discretionary regime, results in a new labour market equilibrium in point $B$, combined with a lower equilibrium real wage and higher equilibrium employment $n_{D}^{*}$. Because of $u=1-n$ the natural rate of unemployment reduces to $u_{D}^{*}$. The long-term Phillips-curve moves to $L P h C_{D}$. The inflation bias diminishes both in the case of policy discretion (by reforms) as in the case of rule-based monetary policy (by commitment). A lower structural unemployment (and, therefore, a lower deviation from the politically desired unemployment) decreases the incentives of politicians to achieve temporary employment gains by unexpected inflation. Compared with the starting situ-

10. Alternatively, labour market reforms might contain the reduction of unemployment benefits, the rise of the efficiency of labour market policy, the substitution of collective by individual wage negotiations, lower minimum wages for young employees, the revision of the laws of wage negotiations (increasing the negotiation power of employees) and the diminishment of both taxes and employment protection. 
ation, an indifference curve which is touched by the short-term Phillipscurve is nearer to the origin. The credibility problem of monetary policy is reduced by structural reforms, combined with a lower equilibrium inflation rate, a lower equilibrium unemployment and a higher welfare.

It is important to note that a rule-based monetary policy eliminates the inflationary bias merely by a credible commitment to an announced target, a device in that respect superior to labour market reforms. The consequence is a lower degree of reforms. Structural reforms of the labour-market cause a higher utility only by the reduction of equilibrium unemployment (no double 'dividend'). They have no additional impact on the inflation bias. The equilibrium unemployment is therefore higher as in the case of discretionary monetary policy. The long-term Phillips-curve $L P h C_{R}$ is consequently located at the right of the long-term Phillips-curve in a discretionary equilibrium.

It could be supposed superficially at this early stage of analysis that discretionary policy does not only lead to a higher degree of structural reforms and lower unemployment but also to higher total welfare. That is exactly what has been implicitly argued in the debate on employment impacts of EMU (as an implicit monetary policy rule) that labour market reforms are more probable outside EMU because of a more discretionary policy (second part of the 'dividend'). On the other hand it has been maintained that structural unemployment will shrink under EM U because transaction costs and exchange rate uncertainty (B elke and Gros [1998]) will be reduced. B ut this narrows the distance between the existing unemployment and the politically desired unemployment (first part of the 'dividend'). For both reasons, the degree of labour-market reform should clearly be lower inside EM U and the start of EMU would lead to welfare losses (for an overview of the debate see Belke [1997b], Belke and Goecke [1999], Calmfors [1997, 1998]).

However, we would like to emphasize that that one decisive point is neglected in the debate. B efore deciding which monetary regime (EM U or its status quo-ante) is advantageous it must be kept in mind that figure 1 consi ders only two components of the loss function, namely the inflation rate and unemployment. The degree of reforms which itself represents an additional cost component of the loss function is only indirectly considered in the first quadrant. A two-dimensional graph like the one above can be used 
only in a very limited way to judge different monetary policy regimes. In order to avoid premature welfare conclusions, a welfare comparison of different monetary policy regimes is carried out in the next chapter. After all, a three-dimensional loss function is part of the model developed in this contribution.

\section{Welfare Comparisons of Different Monetary Policy Regimes}

B efore concluding on the basis of the results in chapter three that discretionary policy with higher equilibrium inflation, a higher degree of reforms and lower unemployment is generally superior to a rule-based monetary policy, a welfare comparison of both alternatives is executed explicitly. Inserting the equilibrium values of employment, reform and inflation under both regimes in the loss-function and comparing the results, leads to:

$$
L(R)-L(D)=\frac{1}{2}(\tilde{u}-\hat{u})^{2}\left\lfloor\frac{{ }^{2}\left({ }^{2}+\right)^{2}}{{ }^{2}\left({ }^{2}+\right)+{ }^{2}}-\frac{2}{+^{2}}-\frac{2}{-}\right\rfloor \leq 0,
$$

respectively

$$
L(R)-L(D)=\frac{1}{2}(\tilde{u}-\hat{u})^{2}\left\lfloor\frac{22}{\left({ }^{2}\left({ }^{2}+\right)+\quad\right)\left(r+{ }^{2}\right)}\right] \leq 0 .
$$

The difference $L(R)-L(D)$ characterizes the advantage of discretionary policy (stochastic shocks are neglected). It turns out that a monetary policy rule is generally superior to discretionary monetary policy. The difference between the welfare under a discretionary regime and a rule-based regime proves to be negative. The degree of superiority, however, is dependent on the parameter values. In some marginal cases, however, the loss under a discretionary regime can correspond to the loss under a rule-based regime.

In order to illuminate these conclusions the model is now calibrated with parameter values which are plausible for Western Europe. The value for $\beta$ is chosen to be 0.5 and corresponds approximately to estimates of German nominal wage rigidities by Layard, J ackman and Nickell [1994], p. 86). The value for $\tilde{u}$ of 8 percentage points cor responds to cur rent intuition and concrete estimates of the NAIRU respectively NAWRU (Non-Accelerating Wage Rate of Unemployment) for the whole time period which is characterized by 
a lack of necessary reforms (except the U.K.) in Western Europe (Belke and Koesters [1999], Koesters and B elke [1996], p. 111 ff., Layard, Jackman and Nickell [1991], p. 436).

The parameters for the inflation aversion $\lambda$ and for the aversion against reforms $\gamma$ are constrained to be one in order to accomplish equal weights for the different arguments in the loss-function (1) (the weight for $(u-\hat{u})$ has already been implicitly constrained to one). The level of the politically desired unemployment ûand the marginal efficiency of structural reforms $\delta$ are computed based on equation (4) $u^{*}=\tilde{u}-r$ (with $\tilde{u}=8,0 \leq r \leq 1$ and the evidence about the level of 'sediment' of unemployment (e.g. search unemployment) which is 'unavoidable' even in flexible labour markets. In the following, the results of a numerical simulation of total welfare (the loss differential between rule-based and discretionary monetary policy) are presented. In these simulations, one parameter after the other is varied while the other parameters are held constant in accordance with Table 1.

Table 1

Parameter Values for the Simulations

\begin{tabular}{|l|cccccc|}
\hline Parameter & $\beta$ & $\gamma$ & $\delta$ & $\lambda$ & $\tilde{u}$ & $\hat{u}$ \\
\hline Value & 0,5 & 1 & 4 & 1 & 8 & 4 \\
\hline
\end{tabular}

Source: Layard, Jackman and Nickell [1991, 1994], Koesters and Belke [1996].

\section{Variation of Inflation Aversion $(\lambda)$}

- The higher the inflation aversion is, the lower is the relative loss of discretionary monetary policy.

- The higher inflation aversion is, the more likely the central banker acts as in the case of a rule-based policy (i.e. ignoring stochastic shocks). In the case of discretionary monetary policy, a higher inflation aversion leads to lower equilibrium inflation (equation (7)) and a lower degree of reform (equation (6c)). Structural unemployment increases.

- With increasing inflation aversion, the total economy loss decreases in the case of monetary policy discretion, since two cost components of the loss 
function (inflation and degree of reforms) decline but at the same time the costs of increasing unemployment do not compensate this additional utility completely.

- For $\gamma$ approaching infinity, the losses of rule-based monetary policy and discretionary policy do not - ignoring stochastic shocks - differ from each other.

The neglect of stochastic shocks simplifies the analysis, since the case of $\lambda$ approaching infinity corresponds to the case of a strict monetary rule without any escape clause. Taking stochastic shocks into consideration, this limiting case corresponds to a feedback-rule.

\section{Figure 2}

The Relative Advantage of Monetary Policy Discretion: Variation in Inflation Aversion $\lambda$

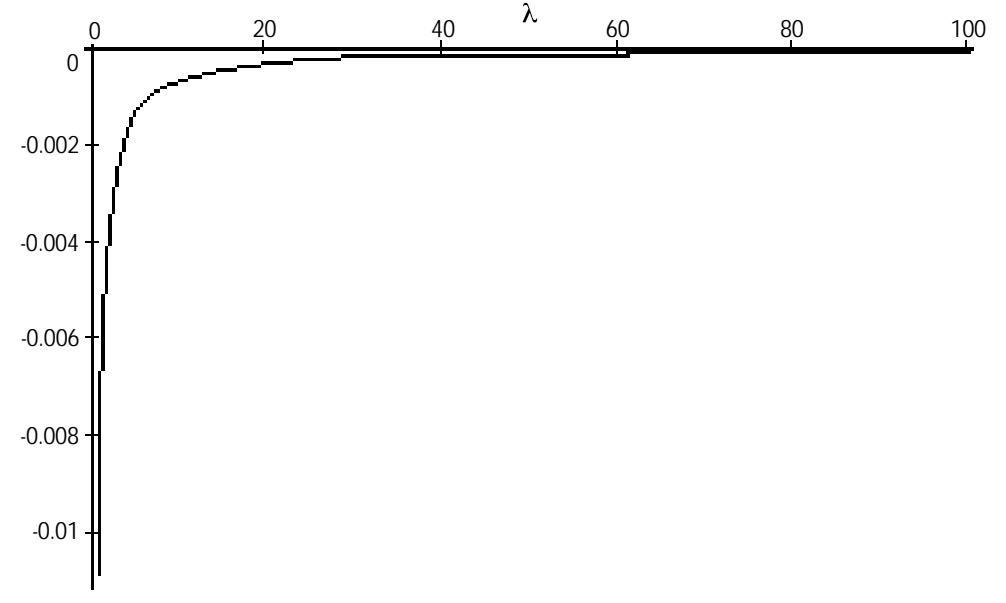

\section{Variation of Reform Aversion $(\gamma)$}

- The higher the marginal political costs of reforms $\gamma$ (in Fig. 3 called gamma for simulation purposes) are, the higher is the relative advantage of rule-based monetary policy.

- With increasing marginal costs of reforms the degree of reforms (equations (6a) and (6c)) decreases under both monetary policy regimes. At the same time, structural unemployment expands. 
- With increasing marginal costs of reforms, the total economy costs of discretionary policy grow faster, since in the case of a monetary policy rule reform costs only have an impact on the degree of reforms, whereas in the case of policy discretion they also have an effect on the inflation bias.

- Expanding marginal costs of reforms increases the inflation bias under a discretionary regime (equation (7)). Credible rule-based monetary policy, however, leads to a constant inflation rate.

Figure 3

The Relative Advantage of Monetary Policy Discretion: Variation in Reform Aversion $\gamma$

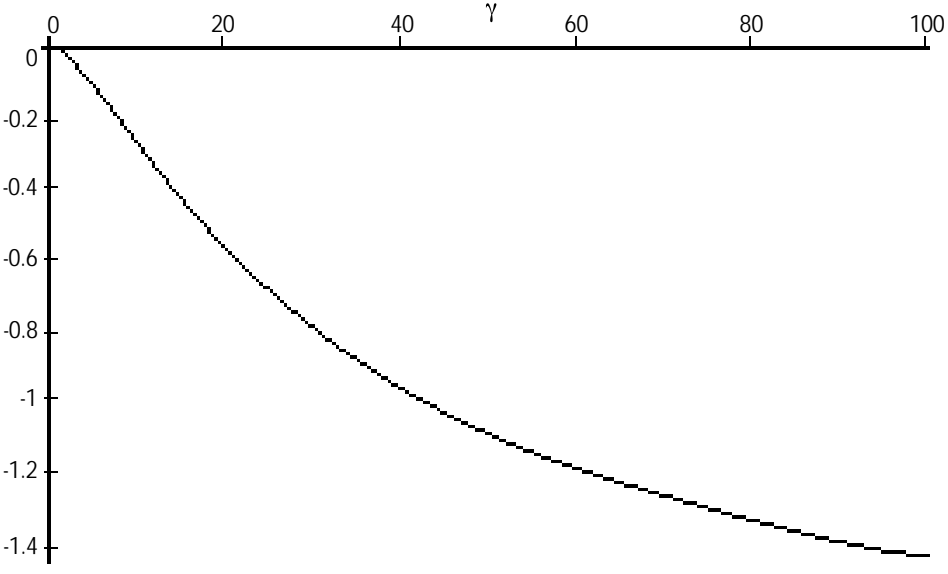

\section{Variation of Nominal Wage Rigidities $(\beta)$}

- The higher the degree of nominal wage rigidities $\beta$ is, the higher is the relative loss with discretion.

- If the degree of nominal wage rigidities increases, neither the degree of reforms nor the equilibrium inflation rate change in a rule-based monetary policy regime (equations (5) and (6a)), since there is ex definition no credibility problem. Independent of the degree of nominal rigidities, politicians do not try to produce unexpectedly high inflation rates.

- Under a discretionary regime, the increase of the "sacrifice ratio" induces a higher average inflation rate (equation (7)), a therefore higher degree of 
reform (equation (6c)) and a lower unemployment. The augmentation of nominal rigidities intensifies the credibility problem of monetary policy. As a consequence, the incentive of politicians to reduce the increasing credibility problem by more labour market reforms expands. However, the costs of a higher average inflation rate and a higher degree of reforms exceed the utility of a lower structural rate of unemployment.

Figure 4

The Relative Advantage of Monetary Policy Discretion: Variation in Nominal Wage Rigidities $\beta$

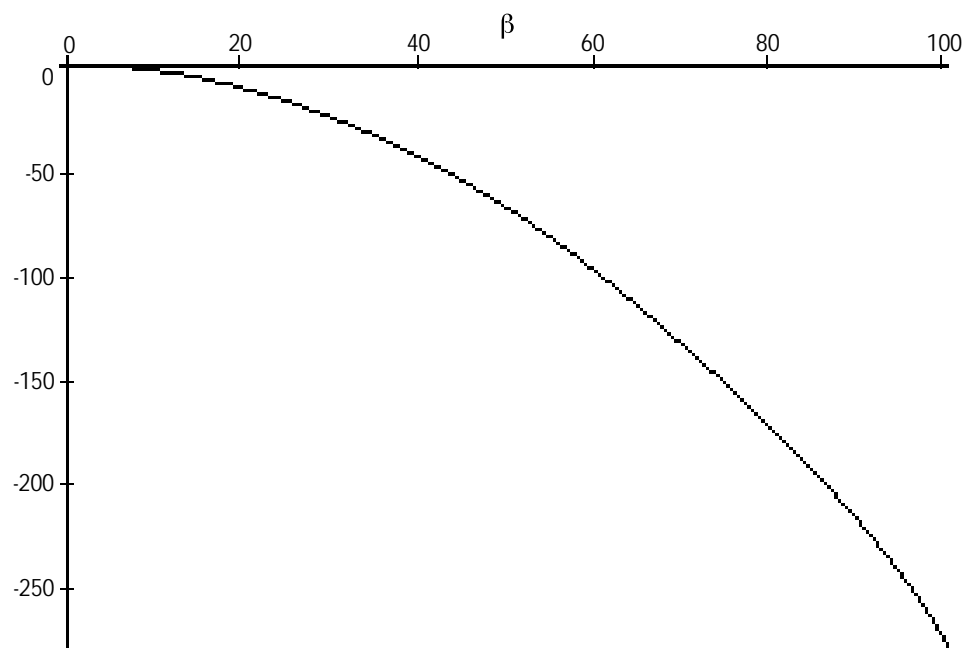

Variation of Marginal E fficiency of Labour Market Reforms ( $\delta$ )

- The higher $\delta$, the marginal efficiency of labour market reforms, is, the lower is the relative loss of discretion.

- With increasing marginal efficiency of structural reforms a higher degree of reforms is realized under both regimes (equation (6a) and (6c)) and a lower rate of structural unemployment is achieved.

- Additionally, a growing marginal efficiency of structural reforms reduces the inflation bias under a discretionary regime (equation (7)). In a rulebased monetar y policy regime the inflation rate remains unchanged.

- Therefore, the loss of an increasing $\delta$ decreases faster under a discre- 
tionar y regime than under a rule-based regime.

Figure 5

The Relative Advantage of Monetary Policy Discretion:

Variation in Politically Desired Unemployment Rate $\delta$

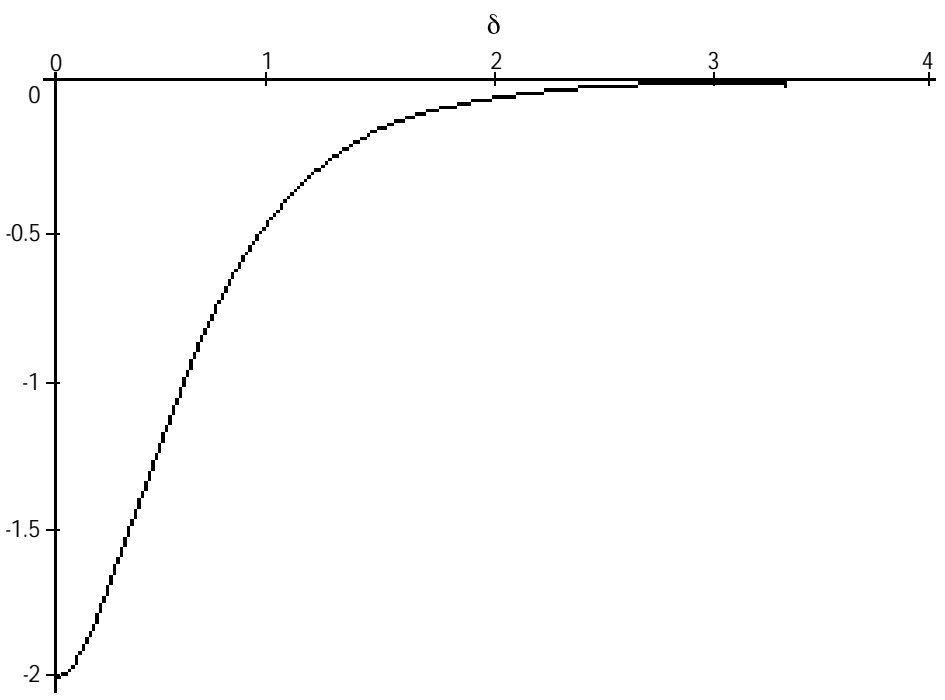

\section{Variation of Target Unemployment Rate (û)}

- The higher û is, i.e. the more "hard-nosed" respectively the more conser vative a government, is, the lower is the relative disadvantage of monetary policy discretion.

- With increasing conser vativeness of the government the degree of reforms is reduced and the inflation rate remains unchanged under a rulebased regime (equations (5) and (6a)).

- The degree of reforms also diminishes with a higher target unemployment rate under a discretionary regime as well. Additionally, also the inflation rate is reduced (equations (6c) and (7)). The utility growth achieved by lower reform costs and a lower inflation rate is higher under a discretionary regime than under a rule-based regime. 
Figure 6

The Relative Advantage of Monetary Policy Discretion: Variation in Politically Desired Unemployment Rate û

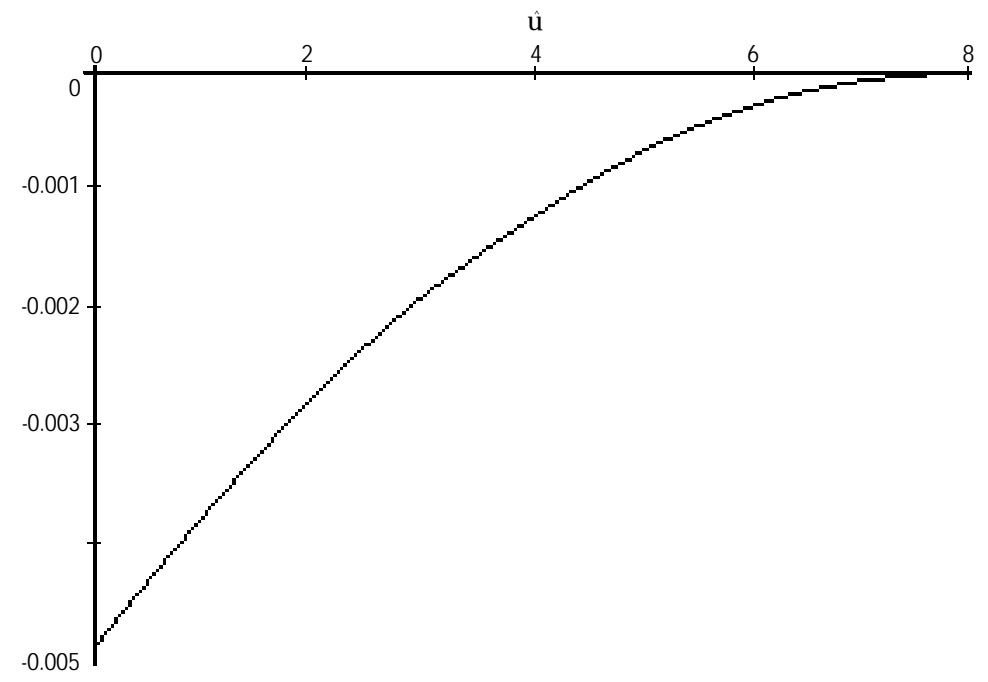

\section{Variation of E quilibrium Unemployment Rate without Reforms (ũ)}

- The relevant part of the curve is at the right of the maximum ${ }^{11}$

- The higher $\tilde{u}$ is, starting from an initial value of 4 (which corresponds to the politically desired unemployment), the higher is the relative disadvantage of monetary policy discretion.

- The higher the equilibrium unemployment rate is in the absence of reforms, the higher is the incentive to inflate in a discretionary regime. With a growing the inflation rate and the degree of reforms rise (equations (6c) and 7)).

- Under a rule-based monetary policy, a higher equilibrium unemployment in the absence of reforms leaves the inflation rate unchanged regime but leads to a higher degree of reforms.

11. The area located left of the maximum represents scenarios in which the political desired unemployment exceeds the structural unemployment without reforms. Because of deflation incentives discretionary monetary policy becomes increasingly sub-optimal. 
Figure 7

The Relative Advantage of Monetary Policy Discretion: Variation in Structural Unemployment $\tilde{u}$

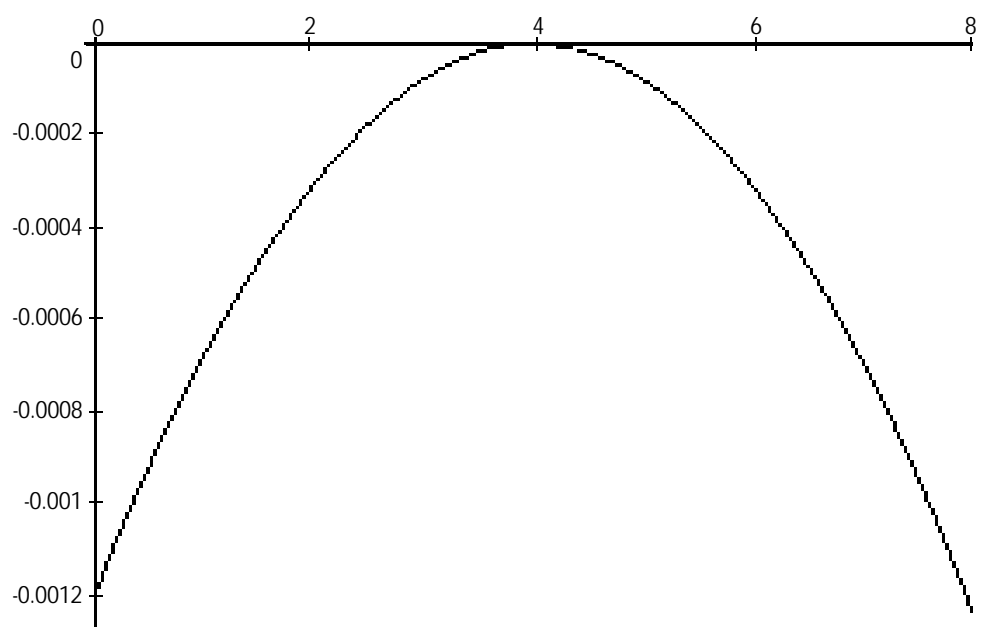

- The loss of a growing equilibrium unemployment rate in the absence of reforms rises to a larger extent in the case of discretion than in the case of a monetary policy rule.

Compared with the formal results gained in section III, the preceding considerations represent some significant research progress. They reveal that it might in fact be very problematic to infer a double 'dividend' from structural labour-market reforms under a discretionary monetary policy regime (and as a logical consequence: from monetary policy outside the European M onetary Union). M oreover, it appears questionable to consider discretionary monetary policy (respectively the implicit alternative to EMU) as generally superior for this reason. It turned out that labour-market reforms under a discretionary monetary regime merely have a double function (instead of a double 'dividend'), namely the lowering of structural unemployment and the dampening of the effective inflation bias. However, a monetary policy rule makes the second function superfluous a priori (Belke and Kamp [1999, 1999a]). The results gained in section III can therefore also be read as follows. Under discretionary monetary policy, labour-market 
reforms turn out to be more trenchant and come out to be more successful for the same reason (as measured by the degree of lowering the structural unemployment rate), simply because they are needed more pressingly. Insofar as a superior (and in the ideal case a perfect) instrument is available for the parallel reduction of the equilibrium inflation rate, namely a strict monetary policy rule, the higher degree of labour-market reforms under discretionary monetary policy only signals a kind of an overshooting. This interpretation has clearly been confirmed by the preceding comparison of total economy welfare under both monetary policy regimes (Belke and Kamp [1999, 1999a]).

\section{Model Extensions}

\section{A. Solving the Need for Reforms: Arguments against a Rule-based Regime}

The incentives for national structural reforms turn out to be higher under a discretionary monetary regime than under a rule-based regime since a lower equilibrium unemployment rate (as a result of structural reforms) itself reduces the inflation bias. The problem of an inflationary bias of monetary policy can be reduced by labour market reforms as a substitute for a monetary policy rule.

If one considers that labour market reforms might reduce both equilibrium unemployment and nominal/ real wage rigidities, the above mentioned effect is even reinforced. The degree of employment reaction to unanticipated monetary policy and also the inflation bias are diminished by diminished rigidities. Taking the impacts of labour market reforms on the degree of nominal wage rigidities into account, the positive effect of discretionary policy on the implementation probability of labour market reforms is underlined. When the effect of unexpected inflation on employment is lowered the incentive of politicians to deviate from a previously announced policy is reduced (Belke and Kamp [1999]).

With respect to the impact of nominal wage rigidities, an additional argument which actually represents a point in favor of monetary policy discretion can be regarded. If downward nominal wage rigidities exist and the 
same time the general level of inflation is low (as currently in most EUcountries), real wage reductions which are caused by labour market reforms and their effects on equilibrium unemployment are achieved only very slowly. A lot of time goes by until successful labour market reforms achieve positive employment gains (Akerlof, Dickens and Perry [1996], Carey [1997], Gordon [1996]). With low inflation rates, a longer term negative relationship between inflation and equilibrium unemployment prevails. This leads to a non-linear long-run Phillips-curve. The lower the level of inflation is, the stronger are the incentives to inflate since the marginal gains of inflation, in the form of a lower natural rate of unemployment, rise with decreasing inflation (Calmfors [1997], p. 24).

In the case of downward rigid real wages, real wage reductions which are necessary for the cutback of equilibrium unemployment and the enforcement of structural changes are not achieved by labour market reforms, at least in the short term. If the resistance of the affected interest groups against the implemented reforms increases simultaneously the endurance of reforms without an accommodating monetary policy gets less and less credible (Belke [1998a]. Uncertainties on the degree of real wage reductions caused by reforms and on the return on investment would lead to a lower present value of a "wait and see" reform strategy in the case of accommodating demand policy (Bean [1998]). Efficient labour market reforms are more likely hold out if they are accompanied by an expansive demand policy. A good timing with a fast and perceptible positive effect on employment reduces political resistance against reforms ("two-handed approach" of Blanchard et al. [1986], see B elke and Koesters [1999], Koesters and Belke [1996]). However, monetary policy can only be varied in the absence of a fixed monetary policy rule. Additionally, one can argue that accommodating monetary policy is the suitable response on a negative supply shock in an inflation targeting regime. If reforms lead to a reduction in nominal wage growth a negative deviation from the national consumer price index and the inflation target might be the result (Calmfors [1998], pp. 32 ff.). 


\section{B. Solving the Need for Reforms: Arguments in Favor of a Rule- Based Regime}

In our model some scenarios are possible where the incentives for structural reforms are higher in a rule-based regime. If employment fluctuations are assessed the more serious the higher is the average rate of unemployment there is a precautionary motive for higher labour market reforms. The marginal utility of an unemployment decrease rises. Therefore, the marginal utility is sufficiently higher under a rule-based regime than under a discretionary regime only if the volatility of employment is higher under the rule-based regime than in the case of policy discretion (Belke [1998a], Calmfors [1998], pp. 34 ff.). Labour market reforms tend to achieve a stronger reaction of real wages to stochastic exogenous shocks. Since monetary policy is (because of the Lohmann trade-off) not unlimitedly at the disposal for stabilizing asymmetric shocks ${ }^{12}$, this effect enhances the marginal utility and therefore the incentive to introduce labour market reforms in comparison to a discretionary regime (see for example Layard, Jackmann and Nickell [1991] and Calmfors [1997]).

Additionally, the intensity of reforms in a rule-based regime is positively dependent on the degree of direct effects on structural unemployment resulting from the monetary policy rule. Employment effects of irrevocably fixed target inflation rates but also the cor responding effects of an accelerated structural change caused by a monetary policy rule and the effects of a credible monetary policy on the wage-setting behavior clearly belong to this aspect (Belke [1997a], Belke [1998], for an overview see Belke [1998a], p. $29 \mathrm{f}$.). If reforms have a positive impact on national structural unemployment the national degree of reforms increases et vice versa; the total effect remains therefore open to debate.

Finally, one can imagine as a not remote possibility that the government might cancel an announced reform or does not realize it at all. If there are two time-inconsistency problems simultaneously, first the traditional one con-

12. See Lohmann [1992]. The Lohmann trade-off describes the trade-off between the utility of a monetary policy rule by commitment and the costs by the loss in flexibility. 
cerning the inflation rate and second the incentive to deviate from a previously announced reform target, a rule-based monetary policy generally achieves a higher degree of reforms than discretionary monetary policy. In this setting, monetary policy rules are defined as regimes where the central bank can credibly commit itself to a target inflation rate and to a reform target. However, a discretionary regime cannot credibly commit itself to previously announce the inflation and the reform target. Therefore, the incentive to realize an announced reform target under a discretionary regime is rather low. From the perspective of a national government, however, any reduction of reform, however, would lead to a subjective cost reduction and a rise in total economy welfare, without any pressure on wage contracts. The reason is that unions and management have already committed themselves to wage contracts. Private agents anticipate this mechanism and are not willing to negotiate low wages. Under a discretionary regime, an equilibrium with too high wages, too low employment and a too low degree of reforms is reached (J ohansson [1998]).

\section{Conclusion}

In order to eliminate structural unemployment in Western Europe to a significant extent, a reform of institutions has to be conducted in order to ensure an adequate functioning of goods- and labour markets. N either fixed monetary policy rules nor discretionary policy can be blamed for the limited functioning of some continental European labour markets and both cannot remove it. However, it is true that the choice of the monetary regime does ex-post not only affect the probability of the elimination of the inflation bias but changes the incentives for the implementation of labour market reforms as well.

According to the results gained in this contribution, a monetary policy rule (like a common monetary policy under EM $U$ from the perspective of a single EMU-in country) does not increase the probability of the implementation of structural reforms substantially. The popular argument made by politicians with respect to $\mathrm{EMU}$ that the elimination of the exchange rate option extends the incentives for painful adjustments on the labour markets cannot be confirmed by economic theory. But for different other reasons 
(e.g. the elimination of not insurable inflation risks, the reduction of transaction costs and the avoidance of the well-known policy lag-problem of national monetary policy) a monetary policy rule might be judged as beneficial for employment prospects. However, the core partial advantage of discretionary policy is that it might enhance the incentives for the implementation of labour market reforms.

H owever, an often neglected central aspect examined in this contribution is the comparison of total economy welfare under both regimes. Discretionary policy does throughout achieve a lower total economy welfare than rule-based monetary policy. This is valid in spite of the higher partial incentives to implement labour market reforms. That is to say total economy welfare under EMU is ceteris paribus superior to the one under discretionary monetary policy from the perspective of a single country. Insofar as a superior instrument is available for the parallel reduction of the equilibrium inflation rate, namely a strict monetary policy rule, the higher degree of labourmarket reforms under discretionary monetary policy outside E M U only signals a kind of an overshooting. The main aim of this contribution was to demonstrate this trade-off between a higher partial incentive for the implementation of labour market reforms (which corresponds to a lower total economy welfare) under discretionary monetary policy and a lower partial incentive to implement labour market reforms (combined with a higher total economy welfare) under a rule-based monetary policy.

\section{References}

Akerlof, G., W. Dickens and G. Perry [1996], "The M acroeconomics of Low Inflation," B rookings Papers on E conomic Activity; 1-59.

Barro, R.J . and D.B. Gordon [1983], "Rules, Discretion and Reputation in a Model of M onetary Policy," Journal of Monetary E conomics 12; 101121.

Barro, R.J . and D.B. Gordon [1983a], "A Positive Theory of M onetary Policy in a N atural Rate M odel," Journal of Political E conomy 91; 589-610.

Bean, C. [1998], "The Interaction of Aggregate-demand Policies and Labourmarket Reform," For thcoming in: Swedi sh E conomic Policy Review.

B eetsma, R. and L. Bovenberg [1998], "The Optimality of a M onetary Union 
without a Fiscal Union," CEPR Discussion Paper 1975, September, London.

Belke, A. [1997], "Zur Politischen Ökonomie der Arbeitslosigkeit, M ancur Olson versus Insider-O utsider-Theorie," Zeitschrift für Wirtschaftspoli tik 46; 243-274.

Belke, A. [1997a], "M aastricht - Implications of a Centralized M onetary and Currency Policy for E mployment in Europe," in J.T. Addison and P.J .J . Welfens, (eds., 1998), European Labor Markets and Social Security Wage Costs, Social Security Financing and Labor Market Reforms in Europe, Springer, Berlin et al.; 195-245.

Belke, A. [1997b], "EWU, Geldpolitik und Arbeitsmarktreformen," IEW Institut für Europäische Wirtschaft Discussion Papers 18, B ochum.

Belke, A. [1998], "Wechselkursfixierung und Beschaftigung - Die Kosten und Nutzen einer EWU," in R.H. Hasse and W. Schäfer, (eds.), Die ökonomischen Außenbeziehungen der EWU - Währungs- und handel spolitische Aspekte, Vandenhoeck \& Ruprecht, Göttingen; 259-295.

Belke, A. [1998a], "EWU, Geldpolitik und Arbeitsmarktreformen," Jahrbuch für Wir tschaftswissenschaften - Review of E conomics 49; 26-50.

Belke, A. [1998b], "Partisan Political Business Cycles in the German Labour-M arket? Empirical Tests in the Light of the Lucas-Critique," Paper Presented at the 1998 EPCS Annual M eeting, Gothenburg/ Sweden, Forthcoming in Public Choice.

Belke, A. [1999], "Integrationswirkungen der Europäischen Wahrungsunion: Zur Komplementarität von Geldpolitik und Arbeitsmarktreformen," in: K.H. Hartwig and H.J. Thieme, (eds.), Finanzmärkte: F unk tionswei se, Integrationseffekte und ordnungspolitische Konsequenzen, Schriften zu Ordnungsfragen der Wirtschaft 58, Lucius \& Lucius, Stuttgart; 247-281.

Belke, A. and D. Gros [1997], "E stimating the Costs and B enefits of EM U: the Impact of External Shocks on Labour Markets," Center for Eco nomic Research Discussion Papers 9795, Tilburg/ NL, also Appeared 1999 in: Weltwirtschaftliches Archiv 135; pp. 1-48.

Belke, A. and D. Gros [1998], "Evidence on the Costs of Intra-European Exchange Rate Variability," Center for Economic Research Discussion Paper 9814, Tilburg/ Netherlands. 
Belke, A. and M. Goecke [1999], "A Simple M odel of Hysteresis in Employment under Exchange Rate Uncertainty," Paper Presented at the E uropean E conometric Society European M eeting 1998, Berlin, Economic Theory Sessions, in: Scottish Journal of Political Economy 46(3); 260 286.

Belke, A. and M. Kamp [1999], "When Do Labour M arket Reforms Achieve a D ouble Dividend? Discretionary versus Rule-based M onetary Policy Revisited," Paper Presented at the Annual M eeting of the European Public Choice Society (EPCS), 7th to 10th April 1999, Lisboa/ Portugal, and at the Annual Conference of the European Association of Labour Economists (EALE), 23th to 26th September 1999, Regensburg/ Germany.

Belke, A. and M. Kamp [1999a], “D ouble 'Dividend' or 'D ouble 'F unction' of Labour M arket Reforms under Discretionary M onetary Policy? A Note on the Calmfors-M odel," in: Jahrbücher für Nationalökonomie und Statistik.

Belke, A. and W. Koesters [1999], "Slow Adjustment to Shocks - In What Way Are the Labour M arket Performances in Western Europe and the U.S. Different?," Forthcoming in: H. Singer, N. Hatti and R. Tandon, (eds.), Globalisation, New World Order Series 19, B.R. Publishing, New Delhi.

Berthold, N. and R. Fehn [1996], "The Positive Economics of Unemployment and Labor M arket Inflexibility," Kyklos 49; 583-613.

Berthold, N. and R. Fehn [1998], “Does EM U Promote Labor-M arket Reforms?" Wirtschaftswissenschaftliche B eiträge des Lehrstuhls fur Volk swirtschaftslehre, Wirtschaftsordnung und Sozialpolitik 19, Universitaet Würzburg.

Blanchard, O. et al. [1986], "E mployment and Growth in Europe - A TwoHanded Approach," in: O. Blanchard et al., (ed.), Restoring Europe's Prosperity, Cambridge, M A; 95-124.

Calmfors, L. [1997], "Unemployment, Labour-M arket Reform and EMU," Keynote Speech at the Ninth Annual Conference of the Association of European Labour Economists (EALE), Aarhus/ Denmark, Published as IIE S Seminar Paper 639, Institute for International E conomic Studies, Stockholm. 
Calmfors, L. [1998], “M acroeconomic Policy, Wage Setting and E mployment - What Difference D oes the EMU M ake?" Paper Presented at the IIES Seminar, September 24, Institute for International Economic Studies, Stockholm, Forthcoming in: Oxford E conomic Policy Review, August.

Carey, K. [1997], "High Unemployment in the OECD; Does the Diagnosis of the 1980s Apply to the 1990s?" American University, Washington, mimeo.

Cukierman, A. and F. Lippi [1998], “Central Bank Independence, Centralization of Wage Bargaining, Inflation and Unemployment - Theory and Evidence," CEPR Discussion Paper Series 1847, London.

Dornbusch, R. and C.A. Favero [1998], "A Red Letter Day?" CEPR Discus sion Paper 1804, February, London.

Gordon, R. [1996], "M acroeconomic Policy in the Presence of Structural M aladjustments," Paper Presented at the OECD Proceedings on Interactions between Structural Reform, M acroeconomic Policies and Economic Performance, Paris.

Grüner, H.S. and C. Hefeker [1996], "M ilitant Labor and Inflation Aversion The Impact of EMU on Labor Union Interaction," Universitat Bonn, SFB 303 Discussion Paper A-539.

Jensen, H. [1997], “Credibility of O ptimal M onetary Delegation, American Economic Review 87; 911 - 920.

Johansson, A. [1998], "The Interaction between Labor M arket Policy and M onetary Policy: An Analysis of Time Inconsistency," Paper Presented at the IIES Seminar, April 28, Institute for International E conomic Studies, Stockholm.

Koesters, W. and A. Belke [1996], "Slow Adjustment to Shocks or True Hysteresis - Lessons from the Different Labor M arket Performances in Western Europe and the USA," Intereconomics 31; 107-121.

Kydland, F.E . and E.C. Prescott [1977], "Rules Rather than Discretion: The Inconsistency of O ptimal Plans," J ournal of Political E conomy 85; 473491.

Layard, R., R. Jackman and S. Nickell [1991], Unemployment, Oxford.

Layard, R, R. Jackman and S. Nickell [1994], The Unemployment Crisis, Oxford.

Lindbeck, A. [1992], "M acroeconomic Theory and the Labor M arket," Euro - 
pean Economic Review 36; 209-235.

Lindbeck, A. [1996], "The West E uropean Unemployment Problem," Wel twir tschaftliches Archiv 132; 609-637.

Lohmann, S. [1992], "The 'O ptimal Degree of Commitment: Credibility and Flexibility," American E conomic Review 82; 273-286.

M cCallum, B.T. [1995], "Two Fallacies Concerning Central-Bank Independence," American Economic Review (Papers and Proceedings) 85; 207211.

M elitz, J. [1997], "The Evidence about the Costs and Benefits of EMU," Swedish Economic Policy Review 4; 191-234.

Nickell, S. [1997], "Unemployment and European Labour M arket Rigidities Europe versus North America," Journal of Economic Perspectives 11; 55-74.

Ozkan, F.G., A.C. Sibert and A. Sutherland [1997], "M onetary Union, Entry Conditions and Economic Reform," CEPR Discussion Paper 1720, November, London.

Persson, T. and G. Tabellini [1993], "D esigning Institutions for M onetary Stability," Carnegie-Rochester Conference Series on Public Policy 29; 5384.

Saint-Paul, G. [1993], "On the Political Economy of Labour M arket Flexibility," in: NBER M acroeconomics Annual; 151-187.

Saint-Paul, G. [1996], "Exploring the Political Economy of Labour M arket Institutions," E conomic Policy 23; 265-315.

Sibert, A.C. and A. Sutherland [1997], "M onetary Regimes and Labour M arket Reform," CE PR Discussion Paper 1731, November, London.

Svensson, L. [1997], "Optimal Inflation Targets, "Conservative" Central Banks, and Linear Inflation Contracts," American E conomic Review 87; 98-114.

Walsh, C. [1995], "Optimal Contracts for Independent Central Bankers," American E conomic Review 85; 150-167. 